\title{
SIGNIFICANCE OF MICRO ALBUMINURIA AS A PREDICTIVE FACTOR IN ACUTE MYOCARDIAL INFECTION
}

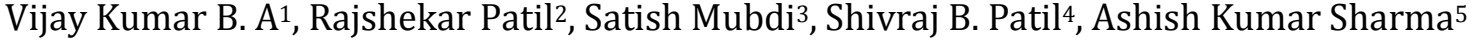

\section{HOW TO CITE THIS ARTICLE:}

Vijay Kumar B. A, Rajshekar Patil, Satish Mubdi, Shivraj B. Patil, Ashish Kumar Sharma. "Significance of Micro Albuminuaria as a Predictive Factor in Acute Myocardial Infection". Journal of Evolution of Medical and Dental Sciences 2014; Vol. 3, Issue 32, August 04; Page: 8825-8828, DOI: 10.14260/jemds/2014/3130

ABSTRACT: OBJECTIVES: A study was undertaken among 50 non-diabetic patients of acute myocardial infarction (AMI) admitted within 24hours of the onset of pain for investigation of the prevalence and significance of microalbuminuria (MA) as a predictor of in-hospital mortality and also to correlate it with other well-established prognostic markers. METHODOLOGY: Spot urinary albumin to creatinine ratio (ACR) was measured in first morning sample on day $1\left(D_{1}\right)$. Day $4\left(D_{4}\right)$ and /or day $7\left(\mathrm{D}_{7}\right)$ homodynamic status was assessed in first clinical by killp's class and the ejection fraction was measured by echocardiography on $\mathrm{D}_{1} \mathrm{D}_{4}$ and /or $\mathrm{D}_{7}$ total 7 days mortality was recorded. RESULTS: MA $(>30 \mu \mathrm{g} / \mathrm{mg})$ was found in $95 \%$ of patients on $D_{1}$ in the group with higher value of MA $(>100 \mu \mathrm{g} / \mathrm{mg})$ on $\mathrm{D}_{1}$ there was significantly more deaths $(\mathrm{p}<0.01)$. Also there was significantly more death increasing or static MA value from $D_{1}$ to $D_{4} / D_{7}(p<0.01)$. Increasing or static MA had a positive correlation with deteriorating killp's class in non-survivors, and also there was a correlation between decrease in left ventricular ejection fraction from $D_{1}$ to $D_{4} / D_{7}$ and an increasing trend in MA over that period. CONCLUSION: MA was found to be a reliable predictor of short-term in -hospital mortality in AMI.

KEYWORDS: Micro-albuminuria, Acute MI, Nephropathy.

INTRODUCTION: Micro-albuminuria (MA) is thought to be a marker of widespread vascular damage. A transient increase stress and is associated with increased mortality. ${ }^{1}$

The aim of this study was to evaluate the incidence of MA in hospitalized patients with acute myocardial infraction (AMI) without other confounding stress, and also to identify any association of MA on day 1 and its subsequent any association trend (from day 1 to 4 or 7) with 7- day mortality attempts were also made to find out the correlation between urinary albumin excretion (UAE) and two well-established prognostic markers of AMI namely, killip's class for hemodynamic status and left ventricular ejection fraction (LVEF). ${ }^{2.3}$

MATERIAL AND METHODS: A total 50 patients (35 male and 15 female, aged 34-67 years with a mean of $52.05 \pm 9.6$ years) of first known AMI, diagnosed as per the ACC/AHA criteria, ${ }^{4}$ were included. Excluded were those patients with any primary or secondary renal disease, diabetic mellitus, abnormal urinalysis, hepatic or renal failure, clinical signs or symptoms of infection, neoplastic disease, and those cases of AMI who died due to unrelated causes.

All the patients were thrombolyzed and routinely given aspirin (150mg daily) and clopidogrel (75mg daily). For comparison, 38 patients (33 males, 25females, aged 37-82 years mean 52.7 \pm 10.1 )

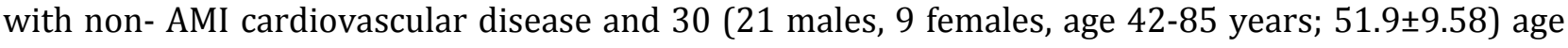
and sex matched controls were also included. 


\section{ORIGINAL ARTICLE}

Spot urine sample was collected on day $1\left(\mathrm{D}_{1}\right)$, within 24 hours of entry into study protocol to measure UAE by immunoturbidimetry, and creatinine by colorimetry using Benedict-Behre reaction. Albumin to creatinine ratio (ACR) value less than $30 \mu \mathrm{g} / \mathrm{mg}$ was considered normal and the value between 30-300 $\mu \mathrm{g} / \mathrm{mg}$ was taken as MA. Subsequent measurement was done on day $4\left(\mathrm{D}_{4}\right)$ and day $7\left(D_{7}\right)$, and the mean of the two values taken.

Those survived less than 7 days, only $\mathrm{D}_{4}$ value was taken. Based on the level of MA on $\mathrm{D}_{1}$, patients were divided into two groups- those with ACR value $>100 \mu \mathrm{g} / \mathrm{mg}$ and those with, $100 \mu \mathrm{g} / \mathrm{mg}$, and mortality between these two groups was compared. Mortality data was also analyzed between those having decreasing MA from $\mathrm{D}_{1}$ to $\mathrm{D}_{4} / \mathrm{D}_{7}$ with those having static or increased values.

Similar to MA, Killip's core and echocardiography LVEF were determined on $\mathrm{D}_{1}$ and subsequently and $\mathrm{D}_{4} / \mathrm{D}_{7}$. Changes in the Killip's score (her increasing or decreasing) and LVEF were compared with the trend in the change in MA.

Variable were expressed as mean \pm standard deviation (SD). The Student's ' $t$ ' test, binomial proportion test, standard error of proportions and Spearmans' rank correlation were performed where appropriate. A p-value of $<0.05$ was considered statistically significant.

OBSERVATIONS: Data is represented in four (5\%) out of 50 patients of AMI did not have any A on $\mathrm{D}_{1}$, rest $95 \%$ (46/50) showed MA, out of them, 18\% (n=9) had ACR $>100 \mu \mathrm{g} / \mathrm{mg}$ and rest $82 \%(\mathrm{n}=41)$ had the value $<100 \mu \mathrm{g} / \mathrm{mg}, 71 \%(\mathrm{n}=10)$ died in the hospital and $29 \%(\mathrm{n}=4)$ survived. In $90 \%$ of those who died, (9 out of 10$)$, the value of MA remained in all the patient with high value $(>100 \mu \mathrm{g} / \mathrm{mg}$ ) who survived the value decline on $D_{4} / D_{7}$ from $D_{1}$. Only $24 \%$ patients $(10$ out of 41$)<100 \mu \mathrm{g} / \mathrm{mg}$ died in hospital.

There was statistically significant $(\mathrm{p}<0.01)$ increase in the number of death in those with $\mathrm{MA}>100 \mu \mathrm{g} / \mathrm{mg}$ on $\mathrm{D}_{1}$.

In $83 \%$ (42 out of 50 ) of patients, the level of MA decreased from $\mathrm{D}_{1}$ to $\mathrm{D}_{4} / \mathrm{D}_{7}$; rest $17 \%$ (8 out $50)$ showed a static or increasing value. In the first group, $22 \%(n=11)$ died. In comparison, $85 \%(11$ out of 13 patients) died in the group showing static / increasing MAs from $D_{1}$ to $D_{4} / D_{7}$. the 2 survived patients in this alter group actually had ACR on $\mathrm{D}_{1}<100 \mu \mathrm{g} / \mathrm{mg}$. there was significantly more change of death with static or increasing level of MAS from $\mathrm{D}_{1}$ to $\mathrm{D}_{4} / \mathrm{D}_{7}(\mathrm{p}<0.01)$.

Comparison was done for demographic parameters (age, sex) clinical characteristics (anterior versus inferior infraction). Lipid status, smoking habits, and drug history (beta-blockers, angioternsin converting enzyme inhibitors) did not reveal significant difference between those with D1 ACT $<100 \mu \mathrm{g} / \mathrm{mg}$ or $>100 \mu \mathrm{g} / \mathrm{mg}$.

At admission, Killip's class was high (means worse) in the group with $\mathrm{MA}(\mathrm{p}<0.05)$. The Killip's class remained static or increased on $\mathrm{D}_{4} / \mathrm{D}_{7}$ in $16 \%$ (8 out of 50 ); $67 \%(\mathrm{n}=8)$ of them ultimately died. However, only $27 \%$ (9 out of 50 ) of patients whose killip's class improved from $D_{1}$ to $D_{4} / D_{7}$ expired. There was a positive correlation between increase in Killip's class and increased/ static MA level amongst those who died.

LVEF improved in 77\% (39 out of 50) and decline or remained static in 23\% (11 out of 50) from $D_{1}$ to $D_{4} / D_{7}$. Only $25 \%$ (10 out of 39 ) in the former group and $56 \%$ (7 out of 11 ) in the later group died. Comparing changes in the LVEF and changes in UAE, there was a positive correlation $(\mathrm{r}=+0.78)$ between decrease in LVEF and increase in level of MA. 


\section{ORIGINAL ARTICLE}

DISCUSSION:MA predicts cardiovascular diseases in both diabetics and non-diabetics. Assessment of MA could an instrument to identity those at an increased risk for coronary artery disease (CAD) in an early stage. ${ }^{5} \mathrm{MA}$ is associated with increased risk of in-hospital on-year, and three year mortality in MI.6,

Out study demonstrated that MA is found in high percentage of hospitalized patients with AMI (95\%) with a rapid fall over next one week (from $62 \%$ on $\mathrm{D}_{1}$ to $28 \%$ on $\mathrm{D}_{4}$ and 145 on $\mathrm{D}_{7}$ ). This suggests that rise in UAE in Ami is essentially an acute phase response.

Patients with MA on D1 $>100 \mu \mathrm{g} / \mathrm{mg})$ had higher mortality. Furthermore, this increased risk was largely confined to the group with higher level of MA $(>100 \mu \mathrm{g} / \mathrm{mg})$ indicating that with higher $\mathrm{MA}$, the inflammatory insult was greater resulting in more death ${ }^{7,8}$. Again a decline in the value of MA from $D_{1}$ to $D_{4} / D_{7}$. was associated with less mortality while increasing / static value had the opposite effect. An increasing or static value had the opposite of MI may be due to intrinsic perpetuation of disturbed vascular hemodynamic once triggered by a vascular insult or difficult in effective clearance of inflammatory response- both indicating a detrimental state of underlying vasculopathy prior to the insult ${ }^{1}$. Expectedly this group had more mortality.

Independent clinical and echocardiography predictors of poor prognosis is after MI are Killip's class ( $>$ or $=2$ on admission) and LVEF $(<40 \%)$ respectively. ${ }^{2,3}$ By showing a good correlation between increasing or continued MA and deteriorating Killip's class, and also a positive correlation between increasing MA with deteriorating LVEF value, MA in this study was further validated as reliable prognostic marker in AMI.

Thus MA predicts7 days morality in hospitalized thrombolyzed AMI patients and can be used as a reliable prognostic marker. ACR value of more than $100 \mu \mathrm{g} / \mathrm{mg}$ on $\mathrm{D}_{1}$ and a static or increased value from $D_{1}$ to $D_{4} / D_{7}$ are strongly associated with increased mortality.

\section{REFERENCES:}

1. Jensen JS. Microalbuminaria and the risk of atherosclerosis: clinical, epidemiological and physiological investigation. Dan Med Bul 2000: 47: 63-78.

2. Killip T ill, Kimball J. Treatment of Myocardial infraction in a coronary care unit: a two year experience with 250 patients. Am J cardiol 1967; 20: 457-64.

3. Obeldat O, Alam M, Divine GW, Khaja F, Goldstein S, Sabbah H. Echocardiographic Predictor of prognosis after first acute myocardial infraction. Am J Cardiol 2004: 94: 1278-80.

4. Antman EM, Anbe DT, Armstrong PW, Bates ER, Green LA Hand M, et al .ACC/ AHA guidelines for the management LA Patients with ST- elevation Myocardial infarction. J Am Colt Cardiol 2004; 44: E1E211.

5. Gerstein HC, Mann JF, Yi Q, Ziman B Dinnenn SF, Hoogweri B, et al . Albuminuria and risk of cardiovascular events death and heart failure in diabetic and non-diabetic individuals JAMA 2001;286:451-6.

6. Berton G, Citro T, palmieri R, Pertucco S, De Toni R, Palatini P. Albumin excretion rate increases during acute myocardial infrctionadn strongly predicts early mortality. Circulation 1997;96:3338-45.

7. Koulouris S, lekatsas I, Karabinos I, loannidis G, Katostaras T, Kranidis A et al. Microalbuminuraia: a stron predictor of 3- year adverse prognosis in nondiabeticpatietsn with acute Myocardial infraction, Am Heart J 2005; 149:840-5. 


\section{ORIGINAL ARTICLE}

8. Berton G, Cordiono R, Palmieri R, Cucchini F, De Toni R Palatini P. Microalbuminuria during acute myocardial infraction; a strong predictor for 1-year mortality. Eur Heart J 2001:22:146675.

\section{AUTHORS:}

1. Vijay Kumar B. A.

2. Rajshekar Patil

3. Satish Mubdi

4. Shivraj B. Patil

5. Ashish Kumar Sharma

\section{PARTICULARS OF CONTRIBUTORS:}

1. Associate Professor, Department of General Medicine, BRIMS, Bidar.

2. Associate Professor, Department of General Medicine, BRIMS, Bidar.

3. Senior Resident, Department of General Medicine, BRIMS, Bidar.

4. Junior Resident, Department of General Medicine, BRIMS, Bidar.
5. Junior Resident, Department of General Medicine, BRIMS, Bidar.

\section{NAME ADDRESS EMAIL ID OF THE} CORRESPONDING AUTHOR:

Dr. Vijay Kumar B. A,

Associate Professor,

Department of Medicine,

Bidar Institute of Medical Sciences,

Bidar.

Email:vijayvb8@gmail.com

Date of Submission: 30/06/2014.

Date of Peer Review: 01/07/2014.

Date of Acceptance: 12/07/2014.

Date of Publishing: 04/08/2014. 